\title{
MORBIDITY PROFILE OF SANITARY WORKERS IN THRISSUR CORPORATION, KERALA
}

\author{
Prabhakumari Chellamma1, Sudhiraj², Arya Vijayakumar ${ }^{3}$
}

1 Professor and HOD, Department of Community Medicine, Govt. Medical College, Thrissur.

${ }^{2}$ Assistant Professor, Department of Community Medicine, Govt. Medical College, Thrissur, Kerala.

3 Junior Resident, Department of Community Medicine, Govt. Medical College, Thrissur, Kerala.

ABSTRACT: Sanitation workers responsibilities in Corporation area are street sweeping \& drain cleaning. These workers are exposed to dirt, infective organisms, hazardous chemicals, sharp objects while working.

\section{OBJECTIVES:}

To study the morbidity profile of sanitary workers in Thrissur Corporation, Kerala.

To study the treatment seeking behavior in these persons.

To study their practices regarding personnel protective measures.

MATERIALS \& METHODS: cross sectional morbidity study was conducted among all sanitation workers corporation area. They were interviewed using pre tested structured schedule. Workers were interviewed after obtaining informed consent.

RESULTS: Among 601 workers 53.6\% were males. 34.4\% workers presented with one acute illness and only $79.2 \%$ soughed medical help. $43.26 \%$ had chronic morbidities and $83.86 \%$ opted modern medicine. $53.9 \%$ of the workers were provided with personal protective equipments and regular use was seen in $18 \%$.

CONCLUSION: Acute illness had significant association with male gender, low education status, large family size, absence of provision of personal protective equipments. Chronic morbidities were associated with males, youlderly group and daily wage workers.

KEYWORDS: Sanitation, Morbidity, Kudumbasree Workers, Personal Protective Measures.

HOW TO CITE THIS ARTICLE: Prabhakumari Chellamma, Sudhiraj, Arya Vijayakumar. "Morbidity Profile of Sanitary Workers in Thrissur Corporation, Kerala". Journal of Evolution of Medical and Dental Sciences 2015; Vol. 4, Issue 89, November 05; Page: 15468-15469, DOI: 10.14260/jemds/2015/2211.

INTRODUCTION: Sanitation workers form the backbone of the civic cleaning system of any society. In India we have nearly 1.2 million sanitation workers. ${ }^{1}$ in a developing country, like India, with limited resources, most of the cleaning process in urban localities remains manual. In Kerala, under the Kerala Municipalities Act, 1994, $\mathrm{road} / \mathrm{street}$ sweeping and drain cleaning forms obligatory responsibility of Municipal Corporation. With improper segregation of waste materials at the source and all types of garbage being disposed on the streets, these workers are exposed to dirt, infective organisms, and other hazardous materials like chemicals, animal excreta, and sharp objects.

As a result of this, they suffer from skin diseases, respiratory and gastrointestinal problems, eye and ear infections and accidental injuries. Most of these diseases (Water borne, air born, Contact) are found to have exposure pathways and most injuries have contact pathways (hepatitis B virus [HBV], human immunodeficiency virus [HIV], Tetanus). Published studies relating to the morbidities of sanitation workers are very few. Scarcity of health data in these workers is a cause of great concern.

Nethercott J. R and Holness D. L assessed the health status of a group of sewage workers in Toronto, Canada.

Financial or Other, Competing Interest: None.

Submission 24-09-2015, Peer Review 25-09-2015,

Acceptance 24-10-2015, Published 05-11-2015.

Corresponding Author:

Dr. Prabhakumari Chellamma,

Professor \& HOD

Department of Community Medicine,

Government Medical College, Thrissur.

E-mail: drcprabhakumari@gmail.com

DOI: $10.14260 /$ jemds/2015/2211.
Investigations of 50 randomly selected workers revealed that many workers reported influenza - like symptoms, cough, sputum production, wheezing, sore throat and skin complaints. ${ }^{2}$ Workers were found to have decreased lung functions by Rylander R, 1983. ${ }^{3}$ Wattetal (1997) investigated 26 sewer men involved in an episode of toxic gas exposure by clinical follow-up, lung function test and measurement of pituitary function; 14 of them developed acute symptoms including sore throat, cough, chest tightness, breathlessness, thirst, sweating and irritability. ${ }^{4}$ A study on Morbidity Profile of swage Workers in Mumbai City found that a large proportion of workers suffered from work related symptomatic morbidities mainly of eye, respiratory, musculoskeletal system, gastrointestinal and skin. ${ }^{5}$ In a study conducted by Sudhir Naik et al, a total of 87 workers were screened, only 1 out of 87 workers used gloves while working and none of the 87 workers used masks or properly covered footwear like boots during the work hours. ${ }^{6}$

\section{AIMS AND OBJECTIVES:}

1. To study the morbidity profile of sanitary workers in Thrissur corporation, Kerala.

2. To study the treatment seeking behavior in these persons.

3. To study their practices regarding personal protective equipments(PPE).

\section{MATERIALS AND METHODS:}

Study design: Cross sectional study.

Study Setting: Urban community Health Centre, Paravattani, Thrissur; coming under Govt Medical College Thissur. 
Study Subjects: All the sanitation workers in Thrissur Corporation.

Study Period: 6 months (January 2014 - June 2014).

Sample Size: All the sanitation workers were included, 800 workers are present in the corporation of which 601 participated in the study.

\section{DATA COLLECTION TOOLS:}

After taking written informed consent, data was collected using:

1. Interview technique using pre-tested semi- structured questionnaire.

2. Anthropometric measurements.

3. Height in cms.

4. Weight in kgs.

5. Body mass index (BMI) was measured using the formula Weight(in kg)/height(in $\mathrm{m}^{2}$ ).

6. Blood pressure measurement using sphygmomanometer in $\mathrm{mm}$ of $\mathrm{Hg}$.

7. Physical examination.

8. Laboratory diagnosis: $\mathrm{Hb}$ in $\mathrm{g} / \mathrm{dl}$, Serum cholesterol in $\mathrm{mg} / \mathrm{dl}$, Fasting blood sugar(FBS) level in $\mathrm{mg} / \mathrm{dl}$.

\section{Variables Under Study:}

1. General information - name, age, gender, address.

2. Socio- demographic features - education, occupation, family type, educational qualification \& occupation type, socio-economic status and details of family members.

3. Acute morbidity : any morbidity in the past 3 months (both reported and at present).

4. Chronic morbidities (both reported and at present).

5. Awareness, availability and practice regarding personal protective equipments.

6. Treatment seeking behaviour.

7. Physical examination and investigations.

METHODOLOGY: Sanitation workers in each of the 55 circles of the corporation were interviewed using a semi structured questionnaire. Physical examination and necessary investigations were done after taking informed consent. Blood investigations like random blood sugar, $\mathrm{Hb}$, serum cholesterol were done free of cost from the center. They were provided with appropriate drugs and a healthcare

\section{Ethical Issues:}

1. A written informed consent was taken from the study participant.

2. The information collected was used only for the purpose of study and strict confidentiality was maintained throughout the study.

3. The cost of the investigations was afforded by the centre.

Data Analysis: Data was coded and entered in MS Excel and analyzed using SPSS.

RESULTS: 601 workers participated in the study and 322 (53.6\%) were males. The mean age of workers being $48.5 \pm 8.2$ with $42 \%(255)$ belonging to $40-50$ age group. The mean family size of the workers were $4.21 \pm 1.39$ $77.7 \%(467)$ of these workers had an educational status of less than $10^{\text {th }} 388(64.6 \%)$ of them were regular corporation workers, 131 daily wage workers, 42 were from kudumbashree and 40 were Adhoc.

$34.4 \%$ (207) of the workers presented with one of the acute illness, the most common being acute respiratory illness (ARI $50.72 \%$ ) followed by gastroenteritis (8.21\%), injuries $(5.79 \%)$ and $28.5 \%$ had a combination of these illness. 164 (79.2\%) out of 207 workers with acute illness had sought medical help. 260(43.26\%) workers had chronic morbidities like anaemia (20.38\%), diabetes mellitus (14.61\%), hypertension (13\%) mainly.

Of the 260 workers with chronic morbidity only 163 $(63.1 \%)$ was on regular treatment. In case of health seeking behavior, $83.86 \%$ opted modern medicine while $5.82 \%$ preferred only AYUSH. 68.75\%(396) was found to utilize government services. Awareness regarding personal protective equipments (PPE) was seen in 512(85.19\%) and 324(53.9\%) of the workers were provided with one of the personal protective equipments; despite this high level of awareness, regular use of PPE was seen only in $18 \%$ of the sanitation workers. Glove was the most commonly used PPE 136(41.97\%) and 164(50.16\%) workers are found to use a combination of PPE.

On examination of workers, their mean BMI was $23.46 \pm 4.15$, the mean systolic BP was $135.3 \pm 20.15 \mathrm{~mm}$ of $\mathrm{Hg}$ and diastolic BP $82.17 \pm 12.20 \mathrm{~mm}$ of $\mathrm{Hg}$. Laboratory diagnosis showed that the workers had a mean Serum cholesterol level of $207.3 \pm 45.8 \mathrm{mg} / \mathrm{dl}$, mean FBS of $95.94 \pm 30.01 \mathrm{mg} / \mathrm{dl}$ and mean $\mathrm{Hb} 12.75 \pm 1.7$. Acute illness had significant association with male gender ( $p$ 0.001), lower educational status ( $p 0.00$ ), daily wage workers ( $p$ 0.001), large family size ( $p 0.03$ ), absence of provision of PPE (0.001) and awareness of PPE ( $p$ 0.004). Chronic morbidities were found to have significant associaton with males ( $\mathrm{p} 0.01$ ), elderly age group (0.004) and in daily wage workers ( $p 0.00)$.

\section{REFERENCES}

1. Tiwari R. Occupational health hazards in sewage and sanitary workers. Indian Journal of Occupational and Environmental Medicine. 2008;12(3):112.

2. NETHERCOTT J, HOLNESS D. Health Status of a Group of Sewage Treatment Workers in Toronto, Canada. American Industrial Hygiene Association Journal. 1988;49(7):346350.

3. Rylander R, Lundholm M; "Sewage Worker Syndrome", Lancet 1976, Aug.28, 2 (1983): 478-79.

4. Watt M, Watt S, Seaton A. Episode of toxic gas exposure in sewer workers. Occupational and Environmental Medicine. 1997;54(4):277-280.

5. Purushottam A. Giri, Abhiram M. Kasbe, Radha Y.Aras; A study on Morbidity Profile of sewage Workers in Mumbai City; International Journal of Collaborative Research on Internal Medicine \& Public Health Vol. 2 No. 12 (December 2010); $450-463$

6. Nayak. S, Shenoi S, Kaur G, Bisen N, Purkayastha A, Chalissery J. Dermatologic evaluation of street sanitation workers. Indian Journal of Dermatology. 2013;58(3):246. 